\title{
Entrevista Stuart McCook
}

O trabalho do historiador canadense Stuart McCook vem se tornando cada vez mais conhecido pelos historiadores ambientais brasileiros. Nascido em Vancouver, na Columbia Britânica, o professor McCook trabalha desde 2003 na University of Guelph, Ontário, Canadá, onde recebe e acompanha um importante número de professores, estudantes e pesquisadores brasileiros e latinoamericanos, auxiliando e orientando em pesquisas de doutorado-sanduíche ou pós-doutorado. Mesmo tendo publicado textos mais voltados à América Espanhola, como o livro "States of Nature", o trabalho do professor é muito bem recebido pelos pesquisadores brasileiros não apenas voltados aos estudos ambientais, mas como veremos nesta entrevista, também junto à História das Ciências e Tecnologia. No Brasil pela terceira vez, esta entrevista foi realizada na cidade de Guarapuava em novembro de 2015, em ocasião da realização da Escola da Sociedade Latinoamericana e Caribenha de História Ambiental. A entrevista foi realizada e traduzida pelo professor Claiton Marcio da Silva. A tradução e revisão técnica foi feita pela professora Samira Peruchi Moretto.

Claiton Marcio da Silva: Gostaríamos de conversar um pouco sobre a sua trajetória. Então, você nasceu no Canadá e realizou grande parte dos seus estudos neste país...

Stuart McCook: Sim, eu iniciei meus estudos na Universidade de Toronto, em física, mas com formação em História e Filosofia das Ciências, em parte porque eu gosto de misturar Humanidades e Ciências. Depois disso, fui para os Estados Unidos e realizei meu mestrado em Science and Technology Studies, no Rensselaer Polytechnic Institute, em Nova Iorque. Como você deve saber, Science and Technology Studies, é um campo interdisciplinar que envolve história, filosofia, antropologia e sociologia das ciências. Ele observa as ciências a partir de diferentes perspectivas humanísticas e das ciências sociais. Foi um programa muito interessante, onde escrevi minha dissertação sobre o primeiro europeu que alegou ter visto um gorila vivo em seu habitat natural. Seu nome é Paul du Chaillu, um personagem muito interessante. Du Chaillu também era interessante porque ele claramente fabricou parte de sua narrativa. Apesar disso, outras partes de sua narrativa parecem ter realmente acontecido, e muito da minha tese é sobre como a comunidade científica conseguia separar as partes das evidências que eram confiáveis, das partes que não eram. Então é uma discussão complexa, e eu consegui a publicação como um artigo de revista na Isis. A partir daí, iniciei o doutorado na universidade de Princeton.

Claiton Marcio da Silva: Quem era seu orientador em Rensselaer?

Stuart McCook: Foi um historiador chamado Thomas Carroll. Iniciei o doutorado em História da Ciência na Universidade de Princeton, sob a tutela de um historiador chamado Gerry Geison (Gerald L. Geison), que é um reconhecido historiador da biologia. Ele se especializou, de maneira estrita, na história, vida e trabalho de Louis Pasteur. De forma ampla, era um especialista em história francesa. Quase todo estudante de doutorado da época, e que pesquisava sobre a historia da biologia, trabalhava com Gerry. Naquela época, eu tinha como temática abordar a História da Ciência no Canadá e nos Estados Unidos, porém sentia que estava um pouco deslocado da minha área. Contudo, passei o verão na Academia de Ciências Naturais da Filadélfia, e lá tive contato com cartas que os naturalistas norte-americanos escreveram quando estavam na América Latina. Fiquei intensamente interessado na questão da ciência e o imperialismo dos Estados Unidos, mudando, a partir daí, o foco da minha pesquisa. Nos dias que se seguiram, decidi passar um tempo em algum lugar da América Latina, e aconteceu que um grande historiador da ciência, Marcos Cueto, estava planejando ir para a Venezuela, no IVIC - O Instituto Nacional de Pesquisa Científica. Fiz os preparativos para a viagem e, no final, ele acabou não comparecendo. Apesar disso, me mudei para a Venezuela e iniciei minhas pesquisas em história natural e ciências agrícolas, basicamente sentindo a biologia tanto pura e aplicada, ou ainda, as ciências dos vegetais de maneira pura e aplicada. E foi lá que uma importante mudança conceitual aconteceu. Cheguei à Venezuela com a intenção de pesquisar sobre ciência e imperialismo norte americano, mas lá percebi que apesar de o imperialismo dos Estados Unidos ter sido uma força importante naquela 
parte da América Latina, não era essa a parte principal, nem a parte mais interessante da história a ser contada. Enquanto o imperialismo dos Estados Unidos permaneceu como uma parte importante do meu trabalho, não era mais o foco principal. Foi nesse período que eu me tornei um historiador da América Latina.

Claiton Marcio da Silva: Quando você se tornou PHD?

Stuart McCook:: 1996

Claiton Marcio da Silva: Como era o cenário da história ambiental nesse contexto?

Stuart McCook: A História Ambiental era um campo relativamente novo.

Claiton Marcio da Silva: Você se considerava imerso neste campo? Ou se considerava um historiador da ciência?

Stuart McCook: Enquanto escrevia minha tese, percebi que uma das maiores questões que me motivava era a quantidade de instituições oficiais ou instituições científicas em criação, na América Latina, entre o final do século XIX e início do século XX: museus de história natural, jardins botânicos, estações experimentais agrícolas, etc. Um dos meus questionamentos era: Por que? O que estava acontecendo? E enquanto escrevia a tese, ficou aparente que parte do que acontecia era a criação de uma nação. Em muitas nações na América Latina, parte da identidade cultural é centrada na ideia dos vegetais, quer seja nos cultivados ou nativos, tanto de maneira simbólica quanto de maneira prática. E outro fenômeno que acontecia era que a América Latina estava passando, pela primeira vez eu diria, por enormes e catastróficas mudanças ambientais associadas à grande exploração de commodities, comuns do início e metade do século XIX. Então comecei não apenas observando os cientistas, mas também me interessei pelo mundo natural que os cientistas estavam observando. Observava, então, os cientistas e através dos cientistas, a paisagem. E foi apenas mais tarde, talvez entre 1993 e 1994, que realmente tomei noção da História Ambiental como uma disciplina. Naquele momento eu estava nos Estados Unidos, e muitos dos artigos fundamentais para a História Ambiental dos Estados Unidos já haviam sido publicados por volta de 1990. É claro que o trabalho de Alfred Crosby é mais antigo do que isso, mas existe uma importante edição do Journal of American History, com contribuições de Alfred Crosby, Donald Worster, William Cronon e outras figuras chave. Então esse realmente foi um momento fundamental, ao menos para mim. E como um latino americanista, eu li Warren Dean, e particularmente para mim, seu trabalho sobre a luta da borracha no Brasil foi muito importante e permanece desta maneira desde sua criação.

Claiton Marcio da Silva: Com a passagem dos séculos XIX para o século XXI, notamos uma crescente discussão sobre tópicos da história ambiental, e o SOLCHA se tornou parte desta cena. Como você vê o crescimento da história ambiental, das histórias das ciências, e de tópicos relacionados ao meio ambiente, na América Latina, e também com relação aos pesquisadores da América do Norte?

Stuart McCook: Acho que estamos novamente em um momento da história onde os problemas ambientais estão entre os problemas mais importantes da América Latina, de uma forma ou de outra. Nas cidades estamos observando sobre questões relativas à poluição do ar, do abastecimento de água. Nos rios observamos as represas, problemas como o rompimento da represa do Rio Doce, que causou grande destruição. Existem questões de mineração, silvicultura, mudanças climáticas, e eu acho que existe uma crescente consciência de que essas coisas não são distintas; são todos fenômenos ambientais ou fenômenos sociais ambientais. E eu acho que a percepção política e a percepção ambiental, dentro da América Latina, está direcionando muitos acadêmicos para estas regiões, na maneira como isso é observado nos Estados Unidos. 
Claiton Marcio da Silva: Como você observa esse crescente interesse na América Latina por assuntos ambientais e o interesse dos historiadores norte americanos sobre esses temas?

Stuart McCook: Por que eu acho que eles estão se tornando interessados?

Claiton Marcio da Silva: Não apenas o seu interesse, afinal somos influenciados por estes trabalho e contribuições.

Stuart McCook: Acho que em parte foi o que eu disse sobre os crescentes problemas ambientais. Mas acho que existem duas questões sobre isso, e observamos isso em muitos trabalhos publicados. Penso que existem dois elementos que motivam as pessoas para os estudos, de uma perspectiva científica em tecnológica. O primeiro é que muito do dano ambiental que foi gerado através dos séculos XIX e XX foi gerado por programas de desenvolvimento baseados no uso intenso de ciência e tecnologia. E atrelado a isso, está a noção da maneira tecnocrática de governar, que é particularmente forte na América Latina. Então existem muitos projetos épicos: represas, pontes, usinas nucleares, construção de estradas, todas são potencialmente problemáticas. Da perspectiva da história da ciência e tecnologia, as pessoas estão buscando entender o papel da ciência e tecnologia e acho que aqueles estão, talvez, olhando para o futuro, estão se perguntado: "existem outras maneiras de organizar ciência e tecnologia para serem mais construtivas"? Acho, de fato, como um historiador, que uma das coisas que gostaria que fosse mais explorada, e mais detalhada nos discursos, é que, tanto entre discursos acadêmicos quanto em discursos do senso comum, se comenta sobre a ciência como algo monolítico, como uma coisa unitária. A ciência fala isso, a ciência fala aquilo, e a tecnologia faz isso. Um estudante, uma vez, me passou uma enquete que questionava: "Você é contra ou a favor da tecnologia?". E esta questão é tão difícil de responder quanto dizer: "Você é contra ou a favor da ciência?". Sou a favor de bombas nucleares? Não. Sou a favor de tecnologias que podem permitir pessoas viverem vidas mais saudáveis e felizes? Sim. Então estas coisas, ciências e tecnologias, não são unitárias. E a ciência não fala com apenas uma voz, ou se move apenas em uma direção. Então na história da América Latina, por vezes, observa-se os agrônomos e biólogos conservacionistas, ambos legítimos grupos de cientistas, trabalhando em direções completamente opostas. E acho que é importante para todos nós construirmos noções mais complexas das ciências, e que isso está realmente acontecendo. Outra coisa interessante, que é mais observável na escrita histórica, é um entendimento mais complexo de como cientistas e engenheiros estão envolvidos em mudanças ambientais. Não é mais uma questão apenas de descobrir quem são os bandidos e os mocinhos, mas também de entender as limitações, as coisas que limitam o comportamento ou o escopo da ação de alguns cientistas, e eu acho essas imagens mais ricas.

Claiton Marcio da Silva: Apenas duas pequenas questões: como você analisa o crescente interesse dos brasileiros sobre o seu trabalho? Existem muitos brasileiros interessados no seu livro e na sua pesquisa, e como você havia estudado espanhol, sua relação anterior era com a América Latina Espanhola.

Stuart McCook: Sim, minha relação era com a América Latina Espanhola, ou pelo menos meus estudos chave eram sobre a América Latina Espanhola. Mas em parte, acho que é porque ao menos na América do Norte, quando você é treinado como um historiador da América Latina, você lê a historiografia de países diferentes. E para mim, muitos dos textos fundamentais que realmente influenciaram a maneira como penso sobre instituições científicas, foram trabalhos como o da Nancy Stepan sobre a Fundação Oswaldo Cruz. Em seu livro, em particular, existe uma seção adorável, já na introdução, onde ela afirma que precisamos repensar nosso entendimento sobre o que significa, para uma instituição científica, "sucesso" ou "fracasso". E foram trabalhos como este, sobre o Brasil, inicialmente, que trouxeram informações para minhas pesquisas sobre América Espanhola. Então é possível notar, em algum nível, que existe um pequeno diálogo. Penso que as questões sobre as quais estou escrevendo são questões que emergiram em muitos países da América Latina, além da influência de alguma historiografia canadense. $\mathrm{O}$ fato de ser canadense me ajuda a formar o tipo de história que eu escrevo porque, 
apesar de o Canadá ter uma grande geografia, somos, em vários sentidos, um país pequeno. Sobre a historiografia do Canada, existe um livro maravilhoso chamado Inventing Canada: Early Victorian Science and the Idea of a Transcontinental Nation, de Suzanne Zeller. O Canada, como muitas nações da América Latina, define-se através do mundo natural, então eu penso que existem problemas comuns ao definir quem somos através do que pode ser cultivado. E o trabalho de pessoas como Regina Horta Duarte, especialmente seu trabalho sobre biologia, também foram muito importantes em formar meu pensamento. Eu sei que muitos gostam do conceito de "Ciência Criola", e também acho que ele adiciona muito no que eu mencionei anteriormente, sobre criar um retrato mais complexo sobre a ciência. Isso porque, novamente, acho que muito da literatura apresenta as coisas de maneira binária. Existe a "ciência colonial" ou "ciência nacional", e isso apenas não funciona. Nenhum desses modelos ou dessas explicações poderiam realmente explicar o que eu observava. Então existem personagens em meu livro como Calos Chardón, um cientista, agrônomo e acadêmico porto-riquenho muito importante que era, simultaneamente, um nacionalista, mas não um separatista. Alguém que prezava por relações próximas com os acadêmicos dos Estados Unidos; acho que ele ocupa seu lugar na ciência crioula. O conceito de ciência crioula é útil porque nos lembra que o relacionamento entre parceiros desiguais pode acontecer - como as relações entre latino americanos e norte-americanos. Cientistas latino americanos podem se beneficiar desta relação, e comumente se beneficiavam, na busca de seus objetivos nacionalistas. Alguém que explorou este conceito muito bem foi Camilo Quintero, um jovem acadêmico que trabalho na Colômbia, e que escreveu um livro maravilhoso — Birds of Empire, Birds of Nation - explorando as relações entre ornitologistas na Colômbia e ornitologistas nos Estados Unidos.

Claiton Marcio da Silva: O que você poderia dizer às pessoas que estão aguardando seu próximo livro?

Stuart McCook: Meu próximo livro será sobre a história da ferrugem do café. Esta temática poderá ser de grande interesse para muitos brasileiros em particular, e latinos americanos, porque lida com o produto que é cultivado praticamente em toda região. Com este livro eu mudei meu foco da América Latina, ou de uma região da América Latina, para um foco global. Uma das coisas que acho serem realmente interessantes, é se desvincular da cultura do café latino americano, para analisar a história das commodities, que é um campo muito rico, e que foca em conexões entre o norte e o sul, do produtor ao consumidor. A história da ferrugem do café me permite explorar relações entre o sul, como relações entre Brasil e Angola, e a Costa do Marfim, como relações muito interessantes entre Brasil e Colômbia, onde existe tremenda troca científica. Esta é, também, uma área na ciência em que os cientistas da América Latina eram os melhores no mundo. Eles não tinham nada a aprender dos cientistas do mundo sobre criação de café, melhoramentos do café e genética do café. Os centros globais de pesquisa eram o "Instituto Agronômico de Campinas" no Brasil, "Cenicafe" na Colômbia entre outros. Do ponto de vista da história da ciência na América Latina é um momento muito interessante. Pode-se caracterizar a excelência científica na periferia, emprestando o título do livro de Marco Cueto (Excelencia científica en la periferia). Mas acho que nesse caso, no mundo do café, esta não é a periferia, e sim o centro, tanto da produção do café quanto da ciência do café. Então estou atualmente trabalhando no manuscrito do livro e espero entregá-lo na metade de 2016, e espero que possamos ver sua publicação em 2017.

Claiton Marcio da Silva: Obrigado.

Stuart McCook: De nada. 